\title{
Garapan Tari "Akegh Cahayegh": Representasi Budaya Ritual Pengobatan Tolak Bala Suku Talang Mamak, Desa Gedabu
}

jurnal tari, teater, dan wayang volume 3 number 2 ,

November 2020

page $96-103$

\author{
Suvina ${ }^{1}$, Martion, dan Ali Sukri \\ Program Studi Seni Tari, Fakultas Seni Pertunjukan, Institut Seni Indonesia \\ Padangpanjang
}

\begin{abstract}
The Creation of "Akegh Cahayegh" Dance: The Culture Representation of Medicinal Ritual on Calamity Reversal of Talang Mamak Tribe, Gedabu Village. The Talang Mamak tribe is a group of people included in the KAT category (Remote Indigenous Community), which is another name for the Tribe of Anak Dalam. The Talang Mamak tribe belongs to the Proto Melayu group. The Talang Mamak tribe's life inspires this source of work in the neighborhood where the workmen live. The craftsmen were very interested in the Mahligai treatment (Tolak Bala), which was located in the inland tribal area of Talang Mamak, Gedabu village in Rakit Kulim sub-district-inspired to work on this culture to survive in today's life. The craftsmen certainly feel proud when this culture is preserved and displayed with new cultivation (innovation) without leaving the medicinal ritual's distinctive features. This work was worked on with the results of the interpretation and imagination of the writer. The values contained in this work are the values of loyalty, obedience, and togetherness. The implicit message conveyed is that the development and change of time is not a barrier for the inland tribe of Talang Mamak, Gedabu village to carry out rituals and preserves ceremony, namely the treatment of Mahligai Tolak Bala as a ritual of cleaning the village.
\end{abstract}

Keywords: preserving culture; obeying; togetherness

\section{Pendahuluan}

Orang Talang Mamak merupakan sekumpulan masyarakat yang terasing dan hidup masih secara tradisional di sehiliran Sungai Indragiri, Provinsi Riau, Indonesia. Dalam kelompok masyarakat ini terdapat sub kelompok yang mereka sebut dengan suku, kemudian dibagi lagi dalam tobo dan unit terkecil mereka sebut dengan hinduk atau perut atau disebut juga puak anak. Suku Talang Mamak merupakan sekelompok masyarakat yang termasuk dalam katagori KAT (Komunitas Adat Terpencil) atau nama lain dari sebutan suku Anak Dalam. Suku Talang Mamak tergolong dalam kelompok Proto-Melayu, yaitu Melayu Tua atau Melayu Pertama, yang terdapat di Kota Rengat, Kabupaten Indragiri Hulu, Propinsi Riau. Suku Talang Mamak terdiri dari dua kata yaitu Talang dan Mamak. Talang adalah sejenis bambu yang tumbuh di lereng gunung, di bukit-bukit, dan dalam hutan yang berbukit; sedangkan mamak adalah saudara laki-laki dari ibu. Mamak dalam kehidupan sehari-hari suku Melayu disebut paman. Oleh sebab itu, Suku Talang Mamak dapat diartikan sebagai mamak yang hidup di daerah berbukit-bukit, di daerah pedalaman Indragiri Hulu. Berdasarkan pengakuannya, nenek moyang suku Talang Mamak berasal dari daerah Gunung Merapi, Sumatera Barat. (M.Simanjuntak, Mailiswin, Saharan, 2012: 4)

\footnotetext{
Alamat korespondensi: Program Studi Seni Tari, Fakultas Seni Pertunjukan, Institut Seni Indonesia Padangpanjang. Email: suvinaviena@yahoo.co.id; HP.: 08228493103.
} 
Kepercayaan Suku Talang Mamak adalah animisme yang tidak mengenal dewa tertentu, tetapi mereka mempercayai bahwa roh-roh nenek moyang, bunyian, makhluk-makhluk halus, malaikat, jin, benda-benda pusaka, dan semua tempat keramat mempunyai kuasa yang gaib. (M.Simanjuntak, Mailiswin, Saharan, 2012: 7) Motto suku Talang Mamak adalah "daripada mati adat, lebih baik mati anak", dan sumpah sakti suku Talang Mamak bagi mereka yang merusak atau ingkar adat adalah "ke atas tak berpucuk, ke bawah tak berurat, ditengah dikerat, kumbang memakan". (M.Simanjuntak, Mailiswin, Saharan, 2012: 5)

Berdasarkan paparan tersebut, pencipta sangat tertarik untuk menggarap sebuah peristiwa budaya berupa pengobatan mahligai (tolak bala) suku Talang Mamak, Desa Gedabu, di Kecamatan Rakit Kulim. Upacara pengobatan tersebut merupakan salah satu adat istiadat budaya maupun kebiasaan yang masih dilaksanakan hingga saat ini. Ketertarikan terhadap peristiwa ini dikarenakan oleh adanya kesempatan bagi penulis untuk menyaksikan peristiwa tolak bala. Peristiwa ini akan digarap dengan interpretasi (penafsiran) dan imajinasi pencipta terhadap ritual tolak bala dan dikemas dalam bentuk karya inovasi (pembaharuan). Pokok permasalahan yang digarap yaitu nilai kesetiaan dari masyarakat pedalaman terhadap budayanya, yaitu pengobatan mahligai sebagai ritual tolak bala, yang dipercaya dan dipatuhi sejak dahulunya. Konflik karya ini ditunjukkan melalui tantangan atas berbagai perubahan dan perkembangan zaman pada saat ini tetapi masyarakat pedalaman itu mampu mengimbangi dan mempertahankan budayanya.

Karya ini digarap dengan menggunakan tema literer dan tipe dramatik. Menurut pencipta, tema dan tipe ini sesuai dengan garapan pencipta, yaitu peristiwa budaya pengobatan mahligai dengan interpretasi dan imajinasi dalam bentuk karya inovasi. Judul karya "Akegh Cahayegh" (Akar Cahaya) menyampaikan pesan bahwa suku Talang Mamak,
Desa Gedabu, merupakan suku yang sangat setia dan patuh adat istiadat, budaya, maupun kebiasaannya. Perkembangan dan perubahan zaman bukan berarti meninggalkan adat maupun kebiasaan tetapi tetap bangga dan menjunjung tinggi budaya ritual pengobatan mahligai (tolak bala).

Karya ini ditampilkan di luar ruangan dengan alasan sesuai dengan konsep pencipta karena dengan tempat pertunjukan semacam ini membantu pencipta merasakan sebagai peristiwa sakral. Setting dan properti diharapkan mampu mendukung "Akegh Cahayegh" sebagai sebuah karya inovasi. Dengan pijakan gerak tari "Rentak Bulean" yaitu tari tradisional suku Talang Mamak, gerak berupa gerak hetak (menghentak) seperti dalam tari "Rentak Bulean". Gerak tersebut melambangkan semangat suku Talang Mamak di Desa Gedabu. "Akegh Cahayegh" menggambarkan masyarakat Desa Gedabu dan menggunakan 12 orang penari, yaitu 7 penari perempuan dan 5 penari laki-laki.

\section{Gagasan atau Ide Cerita}

Garapan karya berawal dari pengalaman dan tempat tinggal pencipta yang tidak jauh dari lokasi penelitian, yaitu daerah suku Talang Mamak, Desa Gedabu. Desa Gedabu menjadi sumber penciptaan tari "Akegh Cahayegh". Pencipta melihat cara kehidupan suku Talang Mamak, Desa Gedabu, dengan perkembangan dan perubahannya yang tidak meninggalkan adat istiadat budaya maupun kebiasaan dalam upacara pengobatan mahligai (tolak bala). Oleh karena itu, masyarakat suku pedalaman memiliki nilai kesetiaan yang tinggi dan patuh terhadap motto dan sumpah sakti yang dibuat dan disepakati oleh masyarakat pedalaman sejak dahulu kala.

Pencipta memulai ide garap karya dengan menekankan adanya konflik dalam masyarakat yang terwujud melalui munculnya rasa kecemasan atau rasa takut musnahnya penerus adat budaya dan kebiasaan masyarakat terhadap upacara 
pengobatan mahligai. Keadaan tersebut tergambar dalam karya "Akegh Cahayegh" yaitu suatu gambaran kehidupan sehari-hari masyarakat suku pedalaman yang tidak lagi saling menghargai kebudayaannya sendiri. Mereka mulai mengacuhkan nasihat-nasihat yang sebelumnya mereka patuhi. Akibat dari perbuatan tersebut terjadi bencana berupa kehancuran dan kesengsaraan bagi suku Talang Mamak, Desa Gedabu. Oleh karena itu, masyarakat suku pedalaman menyesal dan meminta pengampunan dengan cara melaksanakan kembali ritual yang dipercaya memiliki kekuatan gaib dan sakral.

\section{Kajian Sumber Penciptaan}

Seni merupakan salah satu media dalam berkomunikasi, baik secara langsung maupun tidak langsung, sehingga seni mampu untuk menyampaikan pesan. Kualitas seni dapat dilihat dari pesan karya yang disampaikan dan didapatkan oleh penonton. Wujud seni dapat dilihat seperti seni lukis atau gambar, produk ukiran, pahatan, lagu, dan tari. Karya "Akegh Cahayegh" terinspirasi dari sumber visual dan audio visual. Sumber visual yang dimaksud adalah sumber yang dapat dilihat oleh mata seperti peristiwa budaya yang ada di suku Talang Mamak, Desa Gedabu, dalam upacara pengobatan mahligai sebagai ritual tolak bala. Sumber visual ini juga dapat dilihat dari dokumen seperti buku-buku, laporan penulisan, dan foto-foto suku pedalaman; sedangkan sumber audio visual berupa rekaman video.

Karya yang bersumber dari peristiwa budaya suku Talang Mamak, Desa Gedabu, ditampilkan sebagai wujud interpretasi dan imajinasi pencipta dalam bentuk garapan inovatif. Tujuannya adalah menyampaikan pesan bahwa suku Talang Mamak, Desa Gedabu, memiliki komitmen yang kuat dalam menjaga budaya dan mampu mengikuti perkembangan dan perubahan zaman tanpa meninggalkan adat istiadat budaya pusaka lama.
Pokok permasalahan yang digarap yaitu nilai kesetiaan dari masyarakat pedalaman terhadap budaya pengobatan mahligai (tolak bala) yang dipercaya dan dipatuhi sejak dahulu. Hal yang ingin ditunjukkan melalui karya ini berupa cara masyarakat pedalaman untuk mampu mengimbangi dan mempertahankan budayanya dalam berbagai perubahan dan perkembangan zaman pada saat ini.

Karya "Akegh Cahayegh" diwujudkan dalam tiga bagian, yaitu penggambaran masyarakat Desa Gedabu yang damai, penggambaran kekompakan dan kebersamaan masyarakat, dan penggambaran terjadinya konflik dalam diri masyarakat Desa Gedabu. Konflik tersebut diselesaikan dengan kembali melaksanakan ritual dan meminta maaf dari hati yang suci terhadap kecerobohan yang terjadi. Seluruh lapisan masyarakat kembali melaksanakan ritual pengobatan mahligai dalam rangka mengobati desa dan mengobati penghuni desa. Setiap bagian dan adegan karya "Akegh Cahayegh" memiliki suasana yang ditentukan pencipta dan pendukung pertunjukannya. Pendukung karya yang dibutuhkan seperti penari, pemusik, penata seting, penata lampu, dan pendukung karya lainnya membantu dan memiliki peran dalam mewujudkan dan mensukseskan karya inovasi "Akegh Cahayegh". Berikut konsep garap tari "Akegh Cahayegh".

a. Bentuk

Garapan bentuk yang dipilih pencipta adalah bentuk kontemporer. Sebuah garapan tari tentunya memiliki unsur terpenting, yaitu gerak. Pertunjukan tari "Akegh Cahayegh" menggunakan pijakan gerak tari "Rentak Bulean". Tari "Rentak Bulean" ini merupakan tari tradisional suku Talang Mamak dalam melaksanakan sebuah ritual pengobatan. Gerak yang dikembangkan dalam tari "Rentak Bulean" adalah gerak hentak atau menghentak. Alasan pencipta mengambil pijakan gerak tari "Rentak Bulean" dengan gerak hentak yaitu melambangkan rasa semangat suku Talang Mamak pada saat melaksanakan 
sebuah ritual pengobatan. Semangat tersebut diinterpretasikan pencipta melalui gerak hentak kaki penari pada saat bergerak dalam melaksanakan sebuah ritual pengobatan mahligai (tolak bala).

Pijakan gerak tersebut dikembangkan dengan hasil interpretasi dan imajinasi pencipta, seperti volume gerak, ruang karya, tenaga, dan berbagai bentuk pengembangan lainnya. Alasan pencipta mengembangkan kembali gerak tersebut agar menghasilkan gerak baru atau modern yang tidak monoton. Teknik modern, seperti gerak lompat, roling, kayang, gunting, dan beberapa pemahaman gerak yang dikuasai oleh pencipta, dikembangkan dalam wujud karya "Akegh Cahayegh" Desa Gedabu. Hasil perpaduan gerak tersebut menghasilkan gerakan baru dan unik berupa pengembangan desain gerak dan lantai yang tidak monoton.

b. Garapan Isi

Garap isi merupakan penilaian utuh dari sebuah pertunjukan. Karya "Akegh Cahayegh" yang bersumber dari sebuah kebiasaan di suku Talang Mamak, Desa Gedabu, memberikan pemikiran kepada masyarakatbahwabudayayang berkembang bukan hanya sebagai kesenian kreatif tetapi memiliki kajian dan nilai-nilai adat yang terkandung di dalamnya. Nilai-nilai adat ditafsir ulang oleh pencipta melalui bentuk baru sehingga nilai-nilai lama tersebut mampu dinikmati dan diapresiasi dengan baik oleh penonton.

\section{Struktur Garapan}

Bagian I: Bagian ini menggambarkan kehidupan suku Talang Mamak, Desa Gedabu, yang hidup di tengah hutan.

Bagian II: Bagian ini menggambarkan kehidupan suku Talang Mamak, Desa Gedabu, yang hidup di tengah hutan dengan kekompakan, kekeluargaan, dan kebersamaannya.

Bagian III: Bagian ini menggambarkan terjadinya perubahan pola pikir dan pola pandang yang mengakibatkan sebuah konflik dengan hadirnya orang baru yang hidup dengan gaya kekiniannya. Hal ini dapat dilihat dari kostum yang dipakai penari.

\section{Bentuk Karya “Akegh Cahayegh"}

Karya "Akegh Cahayegh" ini menggambarkan kehidupan suku Talang Mamak, Desa Gedabu, yang hidup di tengah hutan. Dengan kehidupan masyarakat yang selalu kompak dalam setiap suka dan duka dalam sebuah desa. Kekompakan tersebut tergambar dari kebiasaannya dalam segi upacara ritual pengobatan. Tempat tinggal suku Talang Mamak, Desa Gedabu, juga menggambarkan kebersamaan dan kekompakan dengan hidup satu rumah satu atap, yaitu rumah adat yang terletak di tengah hutan. Rumah adat tersebut berfungsi sebagai tempat tinggal, tempat untuk musyawarah dan melaksanakan ritual pengobatan.

Bagian 1 adegan 1 ini menghadirkan suasana perkampungan dengan aktivitas suku Talang Mamak, Desa Gedabu, yang hidup di hutan. Tiga orang penari masuk dari samping kiri, kanan, dan belakang rumah adat. Penari yang bergerak tersebut menggambarkan cara masyarakat pedalaman atau perkampungan dalam mencari makanan dan mencari kayu bakar masyarakat suku Talang Mamak, Desa Gedabu.

Adegan 2, enam orang penari muncul dari dalam kolam lumpur dengan menggambarkan kebangkitan atau hidup manusia berawal

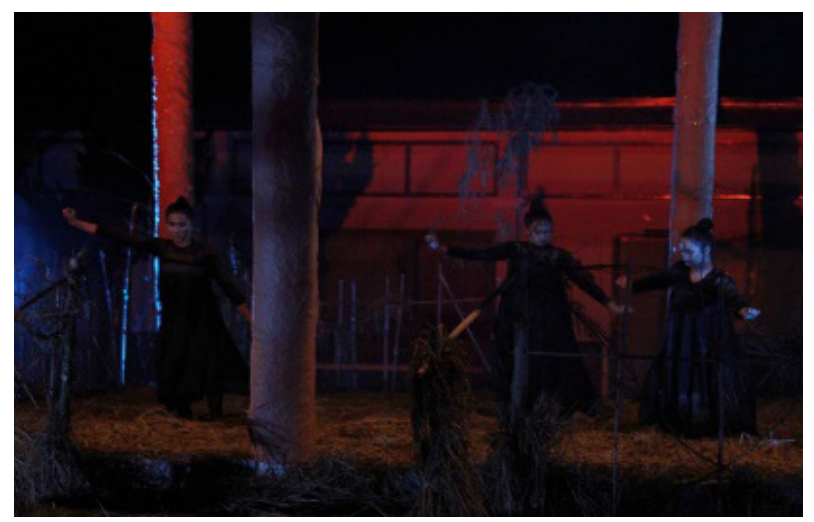

Gambar 1. Pose Gerak pada bagian 1 adegan 1, karya "Akegh Cahayegh". (Sumber: Randi Ifrandi) 
dari tanah dan kembali ke tanah. Kemudian lumpur yang menempel di tubuh penari direpresentasikan sebagai budaya yang sudah melekat dalam diri manusia. Garapan ini menyimbolkan secara tersirat bahwa bangkitnya manusia dan bangkitnya kebudayaan itu bersamaan. Penari di dalam kolam lumpur berjumlah 6 orang, terdiri dari: 2 orang penari perempuan dan 4 orang penari laki-laki. Teknik gerak digunakan teknik kelenturan dengan tetap mengalir dan sedikit sentakan dan ditambahkan sedikit aksentuasi dalam gerak.

Adegan 3 menggambarkan adanya perubahan pada suku Talang Mamak, Desa Gedabu, dengan menggunakan simbol meja bundar sebagai putaran waktu atau terjadinya sebuah perubahan. Seorang penari bergerak di atas meja bundar dengan menggambarkan bahwa dirinya sudah mengikuti perubahan. Perubahan tersebut juga disimbolkan dari kostum penari yang berbeda. Walaupun sudah terjadi perubahan, adat budayanya tetap dijunjung tinggi. Hal ini tergambar

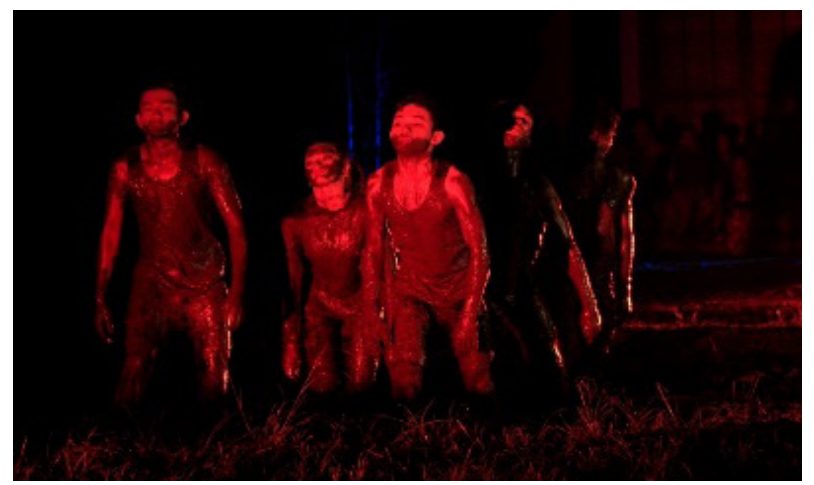

Gambar 2. Pose Gerak pada bagian 1 adegan 2, karya "Akegh Cahayegh". (Sumber: Kurniawan Almi)

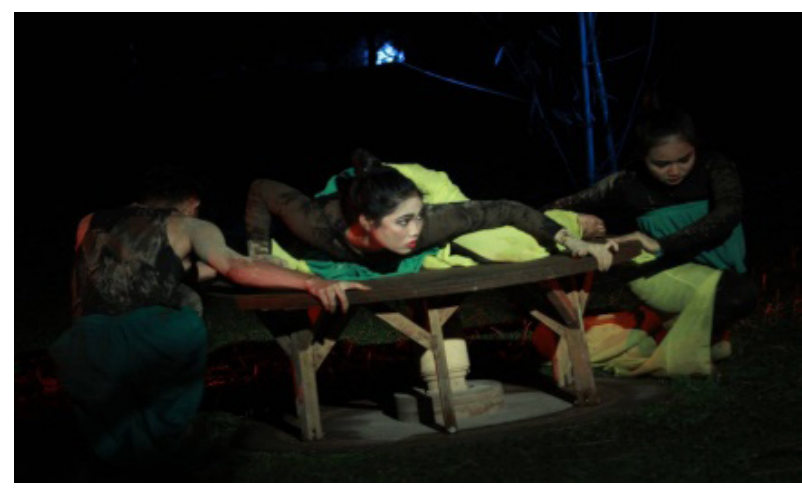

Gambar 3. Pose Gerak pada bagian 1 adegan 3, karya "Akegh Cahayegh". (Sumber: Randi Ifrandi) dari lumpur yang masih menempel di tubuh penari. Tampilan gerak berupa gerak mengalir dan sedikit ada atraksi gerak dengan ekspresi penari tetap tenang.

Bagian 2 menggambarkan kehidupan suku Talang Mamak, Desa Gedabu, yang hidup di tengah hutan dengan kekompakan, kekeluargaan dan kebersamaannya. Adegan 1 ini menggambarkan keseharian suku Talang Mamak, Desa Gedabu, yang kompak. Meskipun sudah terjadi perubahan dalam dirinya yang tergambar dari kostum yang dipakai oleh penari, tubuh penari tetap dilumuri lumpur yang menyimbolkan budaya yang masih melekat. Beberapa penari masuk melewati hutan-hutan dari sudut kanan rumah adat sebanyak 4 orang, 1 penari perempuan dan 3 orang penari laki-laki. Penari tersebut menggambarkan kesibukan suku pedalaman dengan simbol berjalan cepat, jalan lambat, dan berlari-lari. Kemudian penari yang di meja bundar bergabung dan menjadi 7 orang kemudian bergerak rampak di depan rumah adat. Penari tersebut menggambarkan

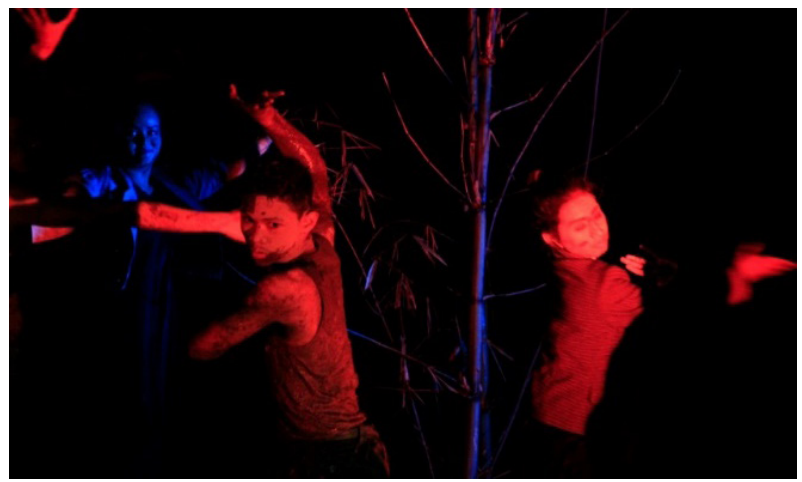

Gambar 4. Pose Gerak pada bagian 2 adegan 1, karya "Akegh Cahayegh". (Sumber: Randi Ifrandi)

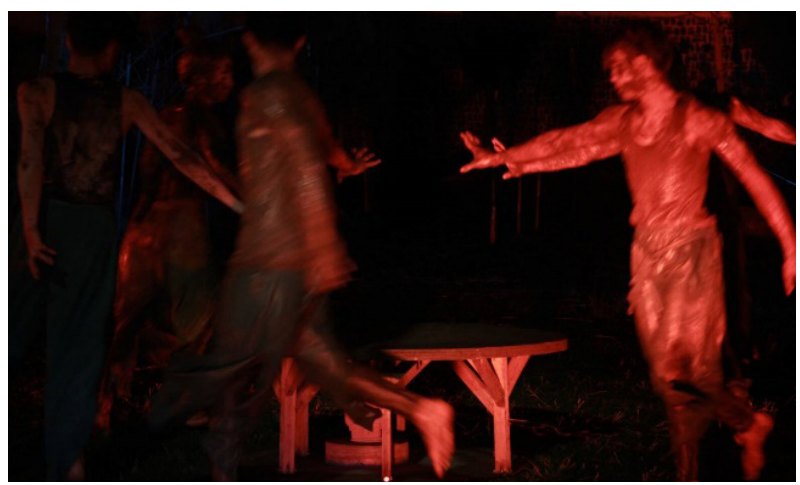

Gambar 5. Pose Gerak pada bagian 2 adegan 2, karya "Akegh Cahayegh". (Sumber: Kurniawan Almi) 
kekompakan dan kebersamaannya yang terlihat dari gerak hentak yang rampak.

Adegan 2 digambarkan dengan penari kemudian masuk dari samping kanan dan kiri rumah adat kemudian bergabung dan bergerak rampak dengan penari yang berada di depan rumah adat. Gerak rampak ini menggambarkan kekompakan masyarakat suku Talang Mamak, Desa Gedabu, dan penari tersebut berjumlah 10 orang penari. Bagian 3 menggambarkan terjadinya perubahan pola pikir dan pola pandangan masyarakat yang mengakibatkan sebuah konflik dengan hadirnya orang baru yang hidup dengan gaya kekiniannya. Hal tersebut dapat dilihat dari kostum yang dipakai penari.

Adegan 1 menunjukkan empat orang penari perempuan masuk dari sudut kanan rumah adat dan melewati hutan-hutan kemudian bergabung dengan suku pedalaman Desa Gedabu. Penari pendatang kemudian berkomunikasi dengan baik kemudian penari bergabung dengan penari suku pedalaman asli. Penari tersebut digambarkan dengan

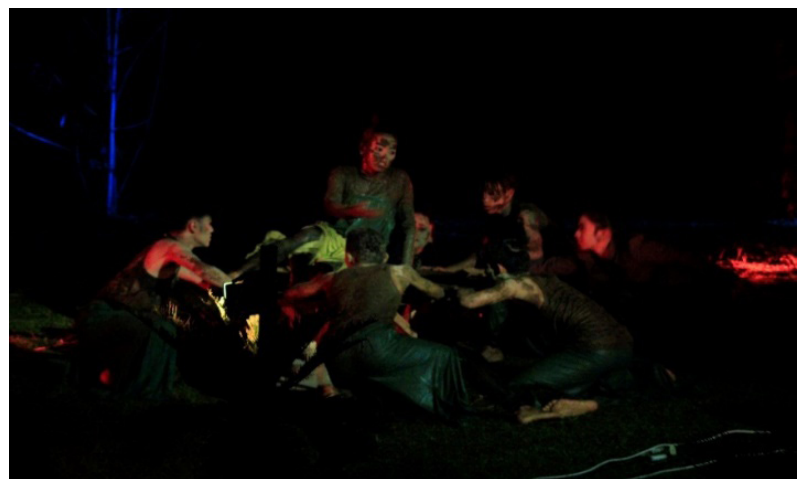

Gambar 6. Pose Gerak pada bagian 3 adegan 1, karya "Akegh Cahayegh". (Sumber: Randi Ifrandi)

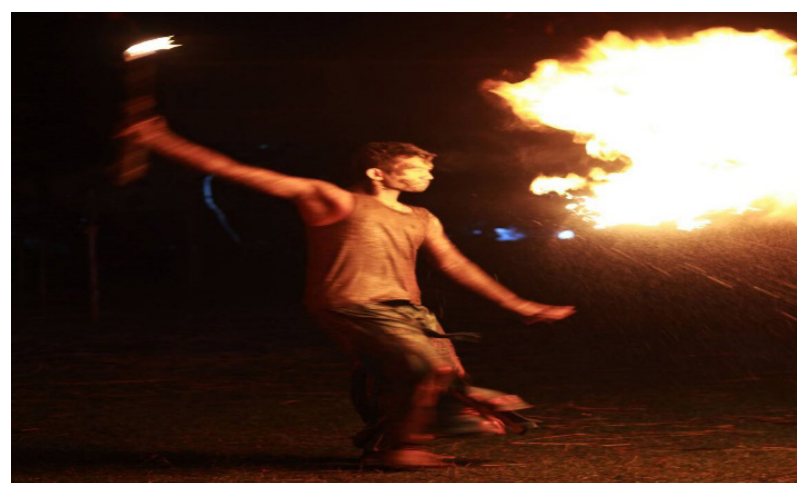

Gambar 7. Pose Gerak pada bagian 3 adegan 2, karya "Akegh Cahayegh". (Sumber: Kurniawan Almi) keceriaannya, bergurau, dan berbahagia bersama-sama hingga lupa diri dan melanggar beberapa aturan adat. Akibat dari perilaku manusia sendiri, kenyamanan pun mulai terganggu. Kepala suku pun merasa terganggu pada saat melaksanakan ritual pengobatan mahligai. Adegan 2 berupa seorang penari laki-laki keluar dari rumah adat yang menggambarkan kepala suku dari suku pedalaman Desa Gedabu. Penari tersebut menggunakan properti obor dengan menyimbolkan kemarahan dari kepala suku yang disebabkan oleh etika masyarakat itu sendiri.

Adegan 3 menunjukkan konflik atau kekacauan dalam sebuah kampung yang dikarenakan oleh suku pedalaman itu sendiri saling menyalahkan satu dengan yang lain. Penari berlari-lari dan ketakutan yang tergambar dari gerak dan ekspresi. Kemudian 4 orang penari masuk dari sudut kanan rumah adat. Mereka bergerak untuk menggambarkan kegelisahan dan ketakutan kehancuran desa yang diakibatkan oleh etika masyarakat itu sendiri.

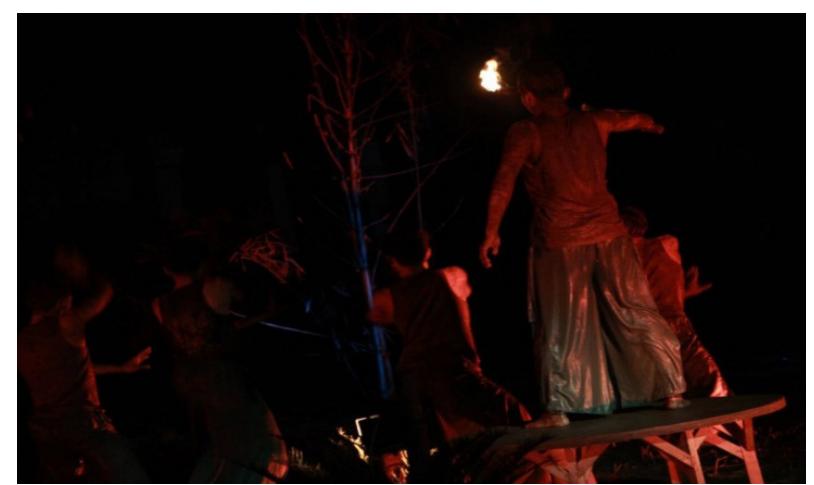

Gambar 8. Pose Gerak pada bagian 3 adegan 3, karya "Akegh Cahayegh". (Sumber: Kurniawan Almi)

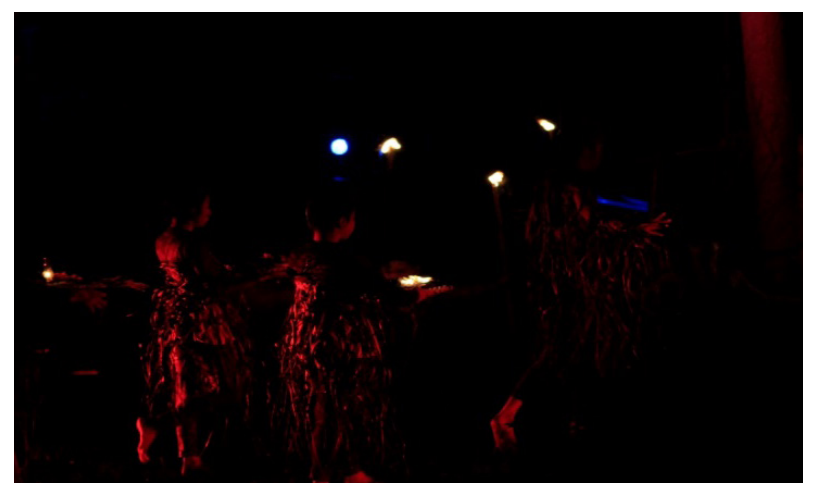

Gambar 9. Pose Gerak pada bagian 3 adegan 4, karya "Akegh Cahayegh". (Sumber: Kurniawan Almi) 
Adegan 4 berupa penyelesaian dengan adanya permohonan kedamaian dan ketenangan bagi desa tersebut. Seluruh masyarakat desa bergabung, baik yang pendatang maupun penduduk asli. Mereka bersama-sama meminta maaf atas kesalahan yang tergambar dengan kembali melaksanakan ritual pengobatan mahligai atau tolak bala. Dalam adegan ini, seluruh lapisan masyarakat kembali menyucikan diri dan menyucikan desa setempat. Pada adegan ini, kepala suku membaca mantra. Rombongan kemudian masuk dari sudut depan kiri penonton dengan membawa keperluan dalam prosesi ritual.

\section{Mantra yang Dibacakan oleh Kepala Suku ${ }^{2}$}

Waaaaaaaloouunnnnnnnnn........

Sebagai sirih pulang ke gagang

Sebagai pinang pulang ke lampuk

Pulang pulih semula kala

Terjemahan:

waaaaaaalooooouuuunnn....

Bagaikan sirih pulang ke tempatnya

(batang)

Bagaikan pinang pulang ke pangkalnya

pulang pulih atau sembuh kembali seperti biasa

Tapung, tapung jati

Datang amas bakati-kati

Tapungko tapung tawar

Datang kidu jangan penawar

Terjemahan:

Tepung tepung jati

Datang emas emas bertubi-tubi

Tepung ini tepung obat

Datang kidu sang pemberi obat

Makan pinang sudara berjumlai

Kepala dibalah keladi jangan seolah-olah

Nang olah nangkan lagi jangan kudar barakit

Ketimun berotali undur penyaki

Terjemahan:

Makan pinang saudara berjumlai

Kepala dibelah keladi jangan seolaholah
Yang olah yang akan lagi jangan kudar

berakit

Ketimun berotali mundur penyakit

Bumi ibu langit bapak

Air sudara kayu daka

Ambun angin sudara nyawa

Rasi tanah balik ka tanah

Rasi air balik ke air

Terjemahan:

Bumi ibu langit bapak

Air saudara kayu daka

Embun angin saudara nyawa

Rasi tanah kembali ketanah

Rasi air kembali ke air

Gandarusa gandarusi

Tebus salah tumbuh dilambah

Kalau berdosa dipuji

Kalau bersalah disembah

Nyawapun kembali kepada Allah

Terjemahan:

Gandarusa gandarusi

Tebus salah tumbuh dilembah

Kalau berdosa dipuji

Kalau bersalah disembah

Nyawa kembali kepada Allah

Setelah terjadi kekacauan dan diakhiri dengan penyelesaian berupa pelaksanaan ritual, kepala suku menghimbau dengan sorakannya dan kembali melaksanakan ritual secara bersama. Pada saat kepala suku membaca mantra, kekacauan pun mulai berkurang hingga kembali damai seperti sedia kala. Penari keluar dari lumpur menyimbolkan permintaan dan permohonan kedamaian seutuhnya. Penari laki-laki yang berada di dalam lumpur keluar dari kolam. Ia membawa obor sebagai simbol menjunjung tinggi budayanya. Seorang penari berjalan keluar dari rumah adat dengan membawa sesajen. Ia berjalan perlahan menuju meja bundar. Penari tersebut disambut oleh penari laki-laki yang berada di meja bundar.

Adegan akhir ini merupakan benang merah dalam karya "Akegh Cahayegh" yang menyimbolkan persatuan meskipun banyak perubahan dan permasalahan yang menimpa mereka. Budaya tetap dijunjung tinggi. Nilai 
kesetiaan tergambar tinggi dalam kehidupan sehari-hari suku Talang Mamak, Desa Gedabu, dalam karya "Akegh Cahayeg".

\section{Penutup}

Garap karya "Akegh Cahayegh" bersumber dari suku Talang Mamak, Desa Gedabu, Kota Rengat, Kabupaten Indragiri Hulu, Provinsi Riau. Karya "Akegh Cahayegh" menampilkan peristiwa budaya ritual pengobatan mahligai (tolak bala) yang terdapat di suku Talang Mamak, Desa Gedabu. Peristiwa budaya tersebut merupakan sebuah ritual adat istiadat budaya suku Talang Mamak, Desa Gedabu.

Karya ini digarap dengan hasil interpretasi dan imajinasi pencipta yang menghasilkan garap karya inovatif dengan judul karya "Akegh Cahayegh". Pokok permasalahan yang digarap berupa nilai kesetiaan dari masyarakat pedalaman terhadap budayanya. Budaya tersebut berupa pengobatan mahligai sebagai ritual tolak bala, yang dipercaya dan dipatuhi sejak dahulunya. Konflik karya ini diselesaikan melalui kemampuan masyarakat pedalaman itu untuk mengimbangi dan mempertahankan budayanya dalam berbagai perubahan dan perkembangan zaman saat ini.

Judul karya ini menggunakan bahasa daerah Melayu Rengat, "Akegh Cahayegh" (Akar Cahaya) yaitu awal dari kehidupan berupa sebuah langkah awal yang dilestarikan dengan baik. Oleh karena itu, suatu kebahagiaan atau cahaya akan selalu menerangi dalam kehidupan. Garapan ini menggunakan penari kelompok sebanyak dua belas orang penari. Pesan dalam garapan ini menyiratkan penggambaran suku Talang Mamak, Desa Gedabu, sebagai kelompok suku yang sangat setia dan patuh serta taat istiadat budaya sebagai titipan atau peninggalan nenek moyang. Perkembangan dan perubahan zaman bukan berarti sebagai kesempatan untuk meninggalkan adat istiadat dan budaya, Hal ini sejalan dengan pepatah Melayu yaitu "tidak akan Melayu hilang di bumi". Pepatah tersebut dapat ditafsirkan bahwa tidak akan semudah itu kebudayaan akan hilang ditelan bumi. Garapan ini diharapkan agar dapat bermanfaat dan bermakna. Karya "Akegh Cahayegh" ini juga diharapkan untuk dapat menambah khazanah budaya lokal dan menambah pengetahuan mengenai Kota Rengat, Kabupaten Indragiri Hulu.

\section{Kepustakaan}

Hadi, Y. Sumandio. 2007. Kajian Tari, Teks Konteks. Yogyakarta: Pustaka Book Publisher.

Hawkins, Alma M. 2003. Terj. I Wayan Dibia. Bergerak Menurut Kata Hati. Jakarta: Isbd.

Hidajat, Robby. 2011. Koreografi \& Kreativitas. Yogyakarta: Kendil Media Pustaka Seni Indonesia.

Isjoni. 2005. Orang Talang Mamak. Pekanbaru: Penerbit Unri Press.

Matsumoto, Davit. 2004. Diterjemahkan Oleh Anindito Aditomo. Pengantar Psikologi Lintas Budaya (People Psychology From a Cultural Perspective).Yogyakarta: Pustaka Pelajar Offset.

Mery, La. (Russel Marwether Hughes). 1975. Dance Compoticion The Basic Elemen. Terjemahan Soedarsono Elemen-Elemen Dasar Komposisi Tari. Yogyakarta: Lagaligo ISI.

Murgianto, Sal. 1993. Ketika Cahaya Merah Memudar. Jakarta: Deviri Ganan.

Murgianto, Sal. 2003a. Mencipta Lewat Tari. Yogyakarta: Manthili.

Murgianto, Sal. 2003b. Koreografi Tari. Jakarta: PT. Ikrar Mandiri Abadi.

Rasyid, Yuziwar. 2008. Makalah. Seni Tari Dalam Perspektif Adat Minangkabau. Disampaikan Pada Seminar Dengan Tema Spirit Hoerijah Adam Dalam Membangun Seni Tari Minangkabau, Padang.

Smith, Jacqualine. 1985. Komposisi Tari Sebuah Petunjuk Praktis Bagi Guru. Yogyakarta: Ikalasari. 